\title{
Early Extracorporeal Membrane Oxygenation for Massive Aspiration during Anesthesia Induction
}

\author{
Namo Kim, M.D., Kwan Hyung Kim, M.D., Jeong Min Kim, M.D., Su Youn Choi, M.D., \\ and Sungwon Na, M.D., Ph.D.
}

Department of Anesthesiology and Pain Medicine, Anesthesia and Pain Research Institute, Yonsei University College of Medicine, Seoul, Korea

\begin{abstract}
Although the incidence is not high in the general surgical population, pulmonary aspiration of gastric contents can result in serious long-term morbidity and mortality. We report a case of early use of extracorporeal membrane oxygenation (ECMO) to correct severe hypoxemia refractory to conventional mechanical ventilation in a patient with massive aspiration of gastric contents immediately followed by acute lung injury during general anesthesia induction.

A 64-year-old woman diagnosed with stomach cancer was scheduled for elective diagnostic laparoscopy. Although there was no sign of gastrointestinal tract obstruction and midnight Nil per Os (NPO) was performed before the operation, pulmonary aspiration occurred during the induction of anesthesia. Despite the endotracheal intubation with mechanical ventilation, severe hypoxemia with hypercapnea persisted. Medical team agreed with applying veno-venous (VV) ECMO, and her blood gas analysis results became stable. ECMO was weaned successfully 9 days after the first aspiration event had occurred. Based on this case, early application of extracorporeal life support can have survival benefits.
\end{abstract}

Key Words: acute lung injury; aspiration pneumonia; extracorporeal membrane oxygenation.

Pulmonary aspiration of gastric contents after regurgitation and vomiting is one of the most serious complications during the perioperative period, and is still a primary cause of anesthesia-related death from pulmonary complications. Aspiration occurs in about 3 per 10,000 patients during the perioperative period in high-risk patients.[1]

Aspiration of gastric contents can result in a range of diseases such as aspiration pneumonitis, aspiration pneumonia, and acute respiratory distress syndrome (ARDS).[2] Acute lung injury and ARDS can result in severe hypoxemia, disability in pulmonary function resulting from acid-related damage, and an increase in mortality from 30\% to 60\%.[1,3] Extracorporeal life support can be helpful in these situations, and there have been many reports on saving lives by applying extracorporeal membrane oxygenation (ECMO) early. We report the benefit of the early application of ECMO in the case of acute lung injury following massive aspiration of gastric contents during the induction of anesthesia.

Received on December 27, 2014 Revised on March 23, 2015 Accepted on March 24, 2015

Correspondence to: Sungwon $\mathrm{Na}$, Department of Anesthesiology and Pain Medicine, Anesthesia and Pain Research Institute, Yonsei University College of Medicine, 50 Yonsei-ro, Seodaemun-gu, Seoul 120-752, Korea

Tel: +82-2-2228-2420, Fax: +82-2-2227-7897

E-mail: nswksj@yuhs.ac

*No potential conflict of interest relevant to this article was reported.

\section{Case report}

A 64-year-old woman suffered from symptoms of nausea and vomiting for about 1 week. She visited a local hospital and was diagnosed with stomach cancer based on endoscopy. Further evaluation in our hospital indicated that the cancer

(c) This is an Open Access article distributed under the terms of the Creative Commons Attribution Non-Commercial License (http://creativecommons.org/ licenses/by-nc/3.0/) which permits unrestricted non-commercial use, distribution, and reproduction in any medium, provided the original work is properly cited. Copyright (c) 2015 The Korean Society of Critical Care Medicine 
was advanced stage adenocarcinoma, location at the lesser curvature of the stomach body, poorly differentiated with serosal exposure and perigastric infiltration. Abdominopelvic computed tomography showed no obstruction of the gastrointestinal tract. The patient was scheduled for elective diagnostic laparoscopy and total gastrectomy (if it was operable). She had a medical history of old pulmonary tuberculosis and renal cystectomy status due to a renal cyst 18 years ago. Preoperative evaluation showed no specific findings on an electrocardiogram (EKG) or chest radiograph, excluding a hemoglobin value of $9.0 \mathrm{mg} / \mathrm{dL}$, possibly due to tumor bleeding.

The patient had a half bowl of liquid for dinner the day before the operation without any discomfort. Room air saturation was $95 \%$ and midnight Nil per Os (NPO) was performed before the operation. A nasogastric tube was not applied because there was no sign of obstruction. There were no pre-medications prior to anesthesia. After the patient arrived at the operating theater, standard monitoring devices were applied including noninvasive blood pressure, electrocardiogram, and pulse oximetry. Before induction of anesthesia, her blood pressure was $154 / 71 \mathrm{mmHg}$, her heart rate was 80 beats/min, and the oxygen saturation $\left(\mathrm{SpO}_{2}\right)$ level was $90 \%$. Although the patient complained of nausea before the induction of anesthesia, the medical team confirmed the fasting duration, which was over $12 \mathrm{~h}$, and considered the nausea to be a symptom of obstruction. For the rapid sequence intubation (RSI), pre-oxygenation was performed with $100 \% \mathrm{O}_{2}$ following administration of 60 mg 1\% propofol (Fresofol ${ }^{\circledR}$, Fresenius-Kabi AG, Bad Homburg, Germany) and $40 \mathrm{mg}$ rocuronium (Rocnium ${ }^{\circledR}$, Hanlim Pharm. Co. Ltd., Seoul, Korea) with remifentanil (Ultiva ${ }^{\circledR}$, GlaxoSmithKline, Co. Ltd., Genval, Belgium) infusion at $200 \mu \mathrm{g} / \mathrm{h}$. After $1 \mathrm{~min}, 10 \mathrm{mg}$ additional rocuronium was administered and mask bagging was performed without peak airway pressure exceeding $10 \mathrm{mmHg}$. Oral suction was performed, where a small amount of saliva was observed in the mouth and the laryngoscope was applied. There was a sudden regurgitation of abundant dark brown colored phlegmatic material in the oral cavity. About $100 \mathrm{cc}$ gastric contents was removed through oral suctioning. After insertion of the oral airway, mask ventilation was resumed. However, saturation levels quickly fell below $60 \%$. Endotracheal intubation was performed immediately by the senior anesthesi- ologist following numerous endotracheal and oral suctions, which removed over $100 \mathrm{cc}$ of watery dark brown content. However, $\mathrm{SpO}_{2}$ fell continuously to an unchecked status combined with bradycardia under 40 beats $/ \mathrm{min}$. Atropine (0.5 mg) was administered; however, cardiogenic collapse occurred. Chest compression was performed with the injection of $0.6 \mathrm{mg}$ epinephrine, which lasted no more than 10 s. Arterial blood gas analysis (ABGA) was measured after asystole was terminated. The results of ABGA ( $\mathrm{pH} 7.22$, carbon dioxide partial pressure $\left(\mathrm{pCO}_{2}\right) 67.3 \mathrm{mmHg}$, oxygen partial pressure $\left(\mathrm{pO}_{2}\right) 33.7 \mathrm{mmHg}$, base excess $(\mathrm{BE})$ $-0.4 \mathrm{mM} / \mathrm{L}$, and arterial oxygen saturation $\left.\left(\mathrm{SaO}_{2}\right) 48.7 \%\right)$ showed severe hypoxemia with hypercapnic respiratory acidosis. Even with endotracheal suctioning and maintaining the inspired oxygen fraction $\left(\mathrm{FiO}_{2}\right)$ up to $100 \%, \mathrm{SpO}_{2}$ was around $65 \%$. Anesthesiologists and surgeons agreed with applying veno-venous (VV) ECMO. While preparing VV ECMO, norepinephrine infusion was started to maintain the blood pressure, and steroid (dexamethasone, $10 \mathrm{mg}$ ) was administered. Fiberoptic bronchoscopy was performed; however, gastric materials that may block the trachea and/ or main bronchus were not visible. Continuous endotracheal suction was performed until ECMO was initiated. Finally, the ECMO catheter was inserted into the right internal jugular vein and the right femoral vein 30 min after the aspiration event had first occurred, and extracorporeal circulation was started $30 \mathrm{~min}$ after the catheter had been placed. From that moment, saturation was maintained over $95 \%$ and the results of $\mathrm{ABGA}$ were $\mathrm{pH} 7.40, \mathrm{pCO}_{2} 38.9 \mathrm{mmHg}, \mathrm{pO}_{2}$ $79.5 \mathrm{mmHg}, \mathrm{BE}-0.6 \mathrm{mM} / \mathrm{L}$, and $\mathrm{SaO}_{2} 95.2 \%$. Pupil reflex was intact. The operation was canceled and the patient was moved to the intensive care unit (ICU).

In the ICU, the patient's mean arterial pressure was maintained over $65 \mathrm{mmHg}$ with norepinephrine infusion (infusion rate: $0.2 \mu \mathrm{g} / \mathrm{kg} / \mathrm{min}$ ), and ventilator care was started with $50 \% \mathrm{FiO}_{2}, 200 \mathrm{~mL}$ tidal volume, a respiratory rate of 8 beats/ min, and $10 \mathrm{cmH}_{2} \mathrm{O}$ PEEP. The initial oxygen fraction, sweep gas rate, and average flow rate of VV ECMO were 100\%, 5 LPM, and 3.5 LPM, respectively. The results of the ABGA were $\mathrm{pH} 7.59, \mathrm{pCO}_{2} 21.6 \mathrm{mmHg}, \mathrm{pO}_{2} 79.8 \mathrm{mmHg}, \mathrm{BE}-0.8$ $\mathrm{mM} / \mathrm{L}$, and $\mathrm{SaO}_{2} 97 \%$. Compared to the preoperative chest radiograph (Fig. 1A), newly developed bilateral consolidations in both the upper lung field and total collapse of right upper lung field were observed on an immediate postopera- 

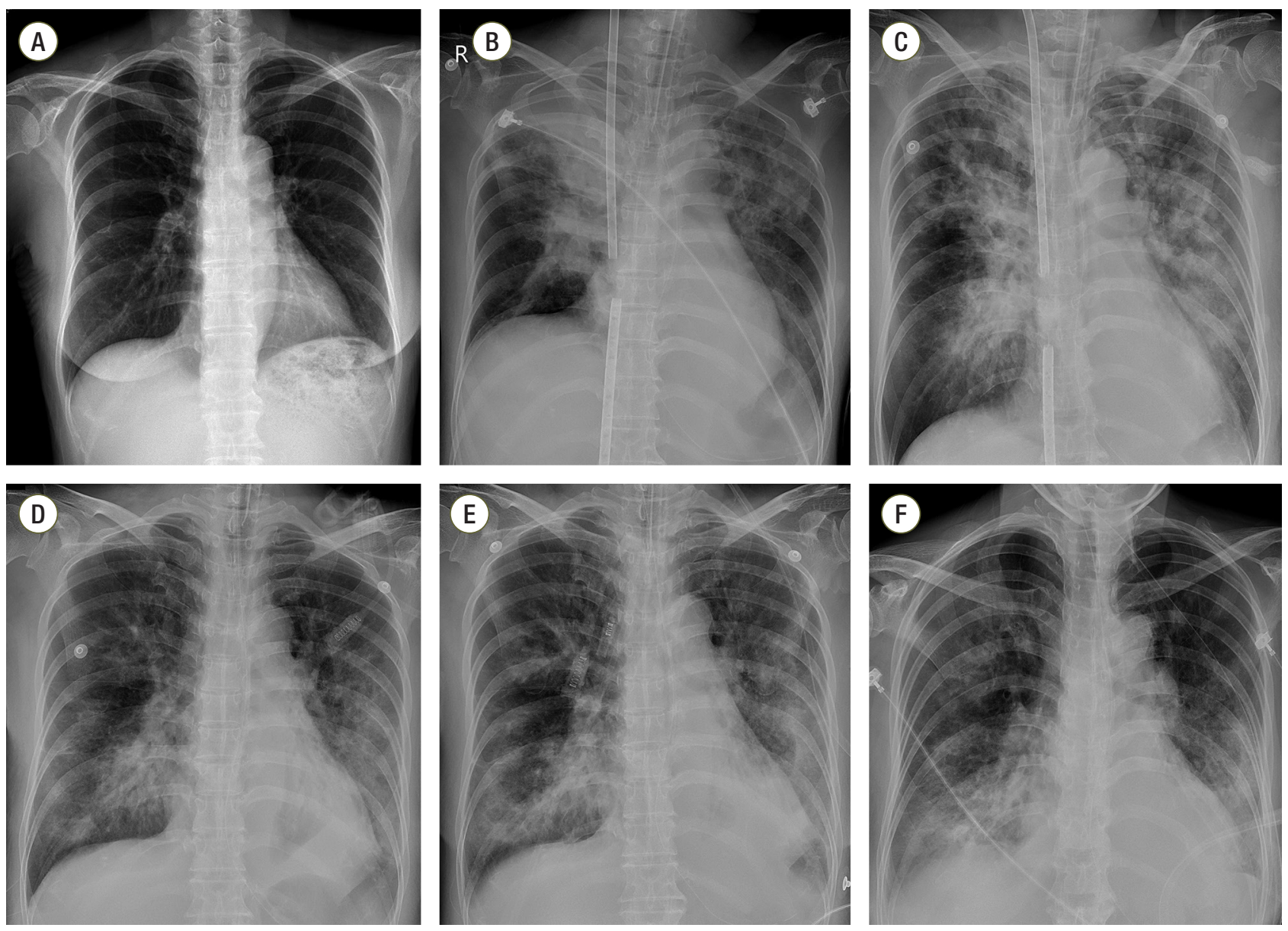

Fig. 1. Chest radiograph; (A) Preoperation; (B) After ECMO; (C) On IOD \#2, ECMO day \#2; (D) On IOD \#6, after ECMO weaning; (E) On IOD \#9, before extubation; (F) On IOD \#9, after extubation.

tive chest radiograph (Fig. 1B). The distance between venous catheters was adjusted to prevent interference of the ECMO flow. After adjusting the catheter distance and lowering the sweep gas rate from 5 LPM to 2 LPM, gas exchange became stable (ABGA; $\mathrm{pH} 7.38, \mathrm{pCO}_{2} 31.9 \mathrm{mmHg}, \mathrm{pO}_{2} 110.3$ $\mathrm{mmHg}, \mathrm{BE}-5.8 \mathrm{mM} / \mathrm{L}, \mathrm{SaO}_{2} 98.7 \%$ ) and norepinephrine was gradually tapered. The treatment plan was to maintain the ECMO and mechanical ventilation using broadspectrum antibiotics with anti-fungal agents until the patient's respiratory system could recover optimal gas exchange ability.

On ICU day (IOD) 2, the right upper lobe total haziness observed on the chest radiograph was slightly improved; however, other bilateral diffuse consolidations were not affected (Fig. 1C). Nonspecific ST wave abnormality on precordial leads of V1-V3 and elevation of cardiac marker (CK $215 \mathrm{IU} / \mathrm{L}$, Troponin-T $0.057 \mathrm{ng} / \mathrm{mL}$ ) was suggestive of heart injury; however, $55 \%$ of the ejection fraction with no other regional wall motion abnormality was supported by transthoracic echocardiography and showed normal cardiac function. Lactic acidosis, which was initially checked $4.9 \mathrm{mmol} /$ L, was resolved. On IOD 6, 6 days after application of ECMO, the patient was weaned from extracorporeal circulation, and was tolerable with conventional ventilator support alone (Fig. 1D). Hemodynamic variables were also stable. ABGA, achieved $1 \mathrm{~h}$ after weaning from ECMO, showed $\mathrm{pH} 7.45, \mathrm{pCO}_{2} 33.7 \mathrm{mmHg}, \mathrm{pO}_{2} 87.5 \mathrm{mmHg}, \mathrm{BE}-0.3 \mathrm{mM} /$ $\mathrm{L}$, and $\mathrm{SaO}_{2} 97.5 \%$. There were no signs of organ failure or complications followed by ECMO. On IOD 9, 9 days after the aspiration event, extubation was performed. Although chest radiograph showed progression of consolidation or collapse of the left lower field with pleural effusion before extubation (Fig. 1E), the patient was tolerable with $60 \%$ 


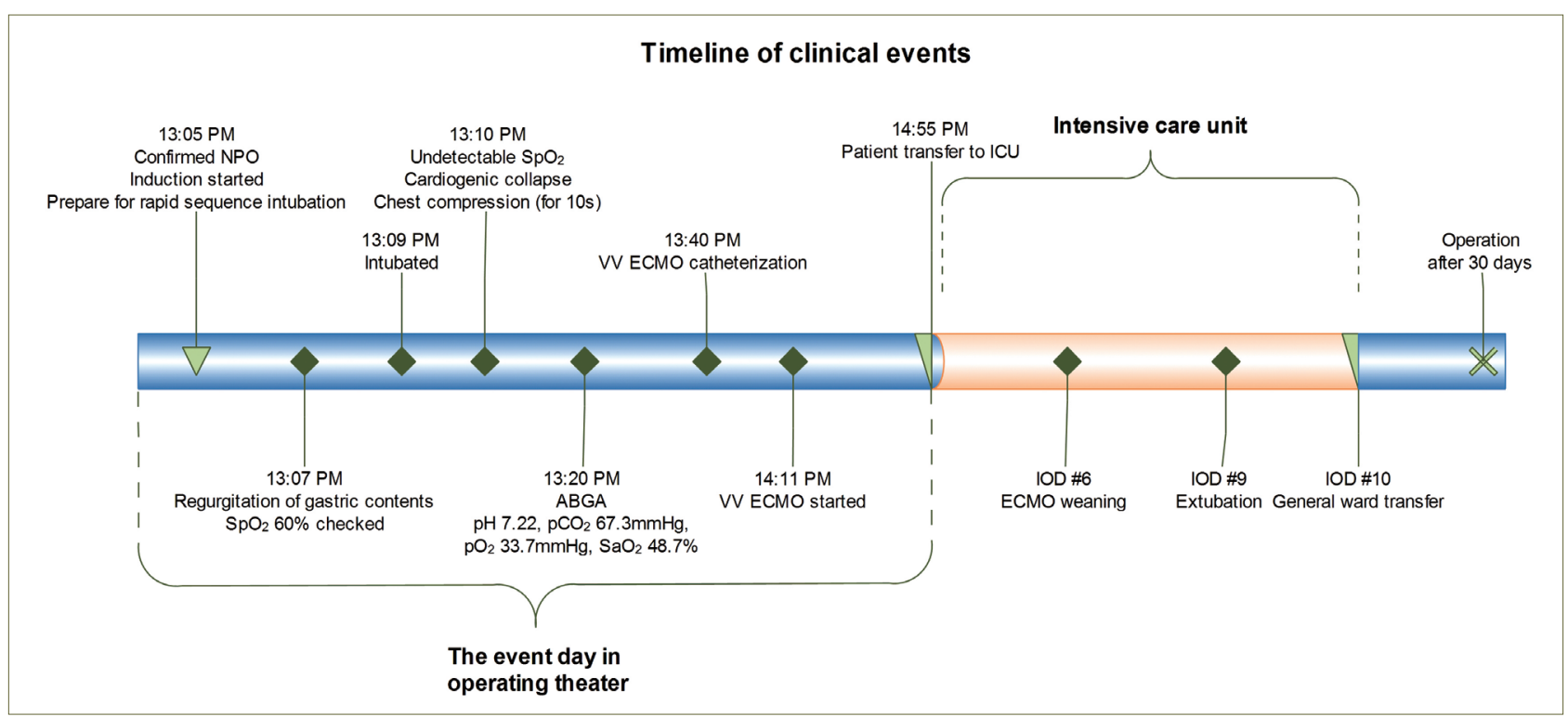

Fig. 2. Timeline of clinical events.

facial mask oxygen supply (Fig. 1F). After 1 day of close monitoring post-extubation, the patient was moved to the general ward and received a palliative total gastrectomy operation when her general condition seemed to be recovered 30 days after the aspiration event (Fig. 2).

\section{Discussion}

In the present case study, aspiration of gastric contents from large amounts of vomiting was unavoidable, despite fasting over $12 \mathrm{~h}$ and applying the RSI technique. Although the patient survived the early application of VV ECMO, it was difficult for the medical team to stabilize her. It took about $1 \mathrm{~h}$ to make ECMO after the event had occurred, and $\mathrm{FiO}_{2}$ of the mechanical ventilator could not be adjusted below $50 \%$ due to an unsatisfactory oxygen partial pressure until the catheter distance was modified.

Based on this case, pulmonary aspiration of gastric contents is one of the most dangerous complications during the perioperative period, especially during the induction of anesthesia. Incidence varies from 1:2,000 to $1: 14,000$ and mortality from $1: 240,000$ to $1: 45,000$.[3] The risk factors of aspiration are obesity, emergency operation, opioid administration, lithotomy, gastro-esophageal reflux, trauma, neurological deficit, pregnancy, gastrointestinal obstruction, and diabetes mellitus. [1,4] Identification of risk factors for pulmonary aspiration is crucial for its prevention. [3] Fasting, pharmacotherapies with the use of antacids, $\mathrm{H}_{2}$ receptor blockers, proton pump inhibitors or prokinetics, stomach decompression with a nasogastric tube, and the RSI technique can be used to prevent aspiration or minimize damage from aspiration, especially for those who have lesions with delayed gastric emptying. RSI consists of proper positioning, sufficient oxygen supply before induction of anesthesia, intravenous administration of opioid and hypnotic agents, use of a rapid acting neuromuscular blocking agent, pressing the cricoid cartilage (known as the Sellick maneuver), and intubation.[5] However, controversy exists regarding the use of pharmacotherapy and the Sellick maneuver in preventing pulmonary aspiration.[3,5]

The clinical course after aspiration varies widely. Aspiration may have no consequences in up to $50 \%$ of cases or may show a mild clinical course,[1] but can also lead to pneumonia or even fatal ARDS. Severe clinical consequences can fall into three categories.[3] One is particle-related complications, in which acute mechanically obstructed airways can result in immediate death from arterial hypoxemia. Another is chemical reactions with acidic gastric contents, which can lead to severe pulmonary edema and inflammatory response. This can proceed in two phases; the first phase is the immediate direct tissue injury phase. After chemical 
burn from the central airway to the alveoli, desquamation of the superficial cell layer with destruction of the alveolar cell occurs within 4-6 h after acid aspiration, resulting in an increase in alveolar permeability and pulmonary edema. [6-8] Increased pulmonary water reduces lung compliance, worsens ventilation-perfusion mismatching, and increases the alveolar-arterial oxygen tension difference. Thereafter, an inflammatory response phase occurs. This phase is characterized by the release of pro-inflammatory cytokines such as tumor necrosis factor alpha (TNF- $\alpha)$ and interleukin- 8 (IL-8), which further promotes a neutrophilic inflammatory response. $[3,9,10]$ Finally, because the gastric contents is not sterile, bacterial infection-related complications, such as severe bacterial sepsis, can occur.

If there is severe hypoxemia and hypercapnic acidemia that cannot be improved by conventional mechanical ventilatory support or massive hemorrhaging that can be lifethreatening (for which cardiac support is required), extracorporeal life support can be helpful. One of the two types of ECMO, veno-arterial (VA) ECMO or VV ECMO, can be applied depending on the clinical situation. VA ECMO can be indicated when the mechanical circulatory support is required during cardiac failure. Typical indications may be acute myocardial infarction, ischemic cardiomyopathy, myocarditis, failure to wean from intraoperative cardiopulmonary bypass, and refractory cardiogenic shock.[11] On the other hand, VV ECMO, considered respiratory ECMO, is recommended for isolated lung failure. This technique, which allows for optimal gas exchange, has gained consensus as a supportive treatment when conventional mechanical ventilation has failed.[12] Case reports with the successful use of ECMO.[13,14] and reports of survival benefit in patients with severe acute respiratory failure[15] support the use of VV ECMO. VV ECMO allows the lung protective ventilation with low tidal volume and a reduction in airway pressure and inspired oxygen fraction during mechanical ventilation, so that the patient's lung can be rested.[16,17] One of the important predictors for successful outcomes is to apply ECMO as soon as possible before the patient falls into catastrophic clinical deterioration.[18] Delayed implementation may cause tissue hypo-perfusion and the progression of multi-organ failure, which can subsequently lead to worsened outcomes. In addition, Camboni et al.[19] reported that prolonged application of VV ECMO was not associated with a higher mortality.

In conclusion, the medical team has to consider the entire situation during induction of anesthesia that can occur in patients at a high risk of aspiration. Once the aspiration of gastric contents occurs, the respiratory system can fall into pneumonitis, pneumonia, and acute lung injury, including ARDS. If severe hypoxemia and hypercapnea occurs and optimal gas exchange cannot be achieved by conventional mechanical ventilation, early application of extracorporeal life support can have survival benefits.

\section{References}

1) Warner MA, Warner ME, Weber JG: Clinical significance of pulmonary aspiration during the perioperative period. Anesthesiology 1993; 78: 56-62.

2) DiBardino DM, Wunderink RG: Aspiration pneumonia: a review of modern trends. J Crit Care 2014; 30: 40-8.

3) Engelhardt T, Webster NR: Pulmonary aspiration of gastric contents in anaesthesia. Br J Anaesth 1999; 83: 453-60.

4) Kluger MT, Short TG: Aspiration during anaesthesia: a review of 133 cases from the Australian Anaesthetic Incident Monitoring Study (AIMS). Anaesthesia 1999; 54: 19-26.

5) El-Orbany M, Connolly LA: Rapid sequence induction and intubation: current controversy. Anesth Analg 2010; 110: $1318-25$.

6) Baum KF, Beckman DL: Aspiration pneumonitis and pulmonary phospholipids. J Trauma 1976; 16: 782-7.

7) Goldman G, Welbourn R, Kobzik L, Valeri CR, Shepro D, Hechtman HB: Reactive oxygen species and elastase mediate lung permeability after acid aspiration. J Appl Physiol 1992; 73: 571-5.

8) Wynne JW, Ramphal R, Hood CI: Tracheal mucosal damage after aspiration. A scanning electron Microscope study. Am Rev Respir Dis 1981; 124: 728-32.

9) Matthay MA, Rosen GD: Acid aspiration induced lung injury. New insights and therapeutic options. Am J Respir Crit Care Med 1996; 154(2 Pt 1): 277-8.

10) Goldman G, Welbourn R, Kobzik L, Valeri CR, Shepro D, Hechtman HB: Tumor necrosis factor-alpha mediates acid aspiration-induced systemic organ injury. Ann 
Surg 1990; 212: 513-9; discussion 519-20.

11) Ventetuolo CE, Muratore CS: Extracorporeal life support in critically ill adults. Am J Respir Crit Care Med 2014; 190: 497-508.

12) Diaz JV, Brower R, Calfee CS, Matthay MA: Therapeutic strategies for severe acute lung injury. Crit Care Med 2010; 38: 1644-50.

13) Wetsch WA, Spohr FA, Hinkelbein J, Padosch SA: Emergency extracorporeal membrane oxygenation to treat massive aspiration during anaesthesia induction. A case report. Acta Anaesthesiol Scand 2012; 56: 797800.

14) Park BH, Chang J, Kim SK, Kang YA, Son JY, Lee KJ, et al: A case of prolonged extracorporeal membrane oxygenation support for severe acute respiratory distress syndrome - A case report. Korean J Crit Care Med 2010; 25: 37-42.

15) Lindskov C, Jensen RH, Sprogoe P, Klaaborg KE, Kirkegaard H, Severinsen IK, et al: Extracorporeal membrane oxygenation in adult patients with severe acute respiratory failure. Acta Anaesthesiol Scand 2013; 57: 303-11.

16) Lafc G, Budak AB, Yener AU, Cicek OF: Use of extracorporeal membrane oxygenation in adults. Heart Lung Circ 2014; 23: 10-23.

17) Bastin AJ, Firmin R: Extracorporeal membrane oxygenation for severe acute respiratory failure in adults: NICE guidance. Heart 2011; 97: 1701-3.

18) Lee SH, Chung CH, Lee JW, Jung SH, Choo SJ: Factors predicting early- and long-term survival in patients undergoing extracorporeal membrane oxygenation (ECMO). J Card Surg 2012; 27: 255-63.

19) Camboni D, Philipp A, Lubnow M, Bein T, Haneya A, Diez C, et al: Support time-dependent outcome analysis for veno-venous extracorporeal membrane oxygenation. Eur J Cardiothorac Surg 2011; 40: 1341-6; discussion 1346-7. 